\title{
A MULHER E O CUIDADO DE SI: DIÁLOGOS POSSÍVEIS
}

\author{
Letícia Veitas Novelli ${ }^{1}$
}

\section{Introdução}

Esta pesquisa tem como intenção problematizar o cuidado de si e os diálogos possíveis entre identidade e alteridade na Grécia Antiga a partir do ponto de vista do lugar da mulher neste período, bem como as formas de mutação do conceito no presente e as possíveis aplicações na história de luta das mulheres na contemporaneidade. O cuidado de si deve ser empregado em um tempo histórico devido às modificações que o conceito passa no decorrer da história. Possui significações e empregos mutáveis no tempo e depende da linha ou vertente filosófica que o insere.

Será inicialmente destrinchado o significado do cuidado de si em Sócrates e como o cuidado de si implica no cuidado para com o outro. Analisar-se-á o panorama de um dos "outros" na sociedade grega antiga, neste caso as mulheres, e como esse conceito poderia ou não ser utilizado/vivenciado por estas mulheres. Por fim, concernirá sobre as maneiras que o cuidado de si se revela nas mulheres contemporâneas e qual a importância deste autocuidado que leva ao autoconhecimento nos dias de hoje.

Como fundamentação teórica da pesquisa, serão utilizados os autores Foucault (2006), com o livro A hermenêutica do sujeito, no qual analisa o conceito do cuidado de si e suas mutações no tempo, e Lessa (2004), com o livro O feminino em Atenas, que faz uma análise das mulheres atenienses utilizando, como documentação para sua análise, elementos arqueológicos, vasos e pinturas, bem como livros escritos por filósofos da época. Utilizar-se-á também a autora Perto (2017) para demonstrar, analisar e problematizar as lutas femininas do século XXI, bem como, explicar como estas lutas sociais são exemplos de autocuidado e não apenas um cuidado egoísta.

Ademais, espera-se contribuir com uma visão diferente sobre o cuidado de si e demonstrar como este conceito, em Sócrates, não pode ser aplicado a todas as esferas da sociedade ateniense antiga, mas que com as mutações passadas até o presente este conceito transformouse e contribuiu para mudanças sociais expressivas.

\section{O cuidado de si e o cuidado do outro para Sócrates}

Não há como utilizar os conceitos de "cuidado de si" e o "ocupar-se consigo mesmo" sem categorizar inicialmente sobre o conceito e seu surgimento. Segundo Foucault (2006), pesquisase muito sobre o cuidado de si em Sócrates e a prática de Alcebíades, contudo, estes conceitos são mais antigos que o próprio Sócrates. Além do mais, Sócrates foi um dos filósofos mais importantes da História da Filosofia e fez da frase inscrita no templo de Apolo em Delfos "conhece-te a ti mesmo" um de seus princípios mais estimados. (SANTOS, 2008).

A filosofia de vida difundida por Sócrates deve-se ao modo de vida que os atenienses levavam. Segundo Sócrates, os atenienses ocupavam-se "[...] com tantas coisas, com vossa fortuna, com vossa reputação, não vos ocupais com vós mesmos.” (FOUCAULT, 2006, p. 8). Para Sócrates a importância final da vida deve ser a ocupação e o cuidado consigo mesmo, e se o condenassem a morte estariam cometendo o erro de não ter alguém capaz de incitá-los a cuidar de si mesmo.

\footnotetext{
${ }^{1}$ Mestranda em Ensino (PPGEN-UTFPR-LD). Especialista em Filosofia Moderna e Contemporânea (UEL, 2017). E-mail: novelli_leticia@hotmail.com.
} 
Foucault (2006) coloca que Sócrates via-se como esta pessoa capaz de incitar os atenienses a mudarem o cuidado consigo mesmo. Mas pontua que nada mais era que um instrumento dos deuses para esta tarefa, substituível com facilidade ou mediante o interesse dos deuses. Outro elemento circunstancial sobre o cuidado de si, é que Sócrates ao incitar os outros, mais exclusivamente, Alcebíades, não teria como ocupar-se consigo próprio, negligencia, desta forma, outras atividades tidas como de seu interesse, por exemplo, sua própria fortuna e a carreira política (FOUCAULT, 2006).

Sócrates entendia o processo de cuidar e incitar o outro como um sacrifico necessário, pois traria o despertar às pessoas. Além de entender que a necessidade dos herdeiros de ocuparem-se com grandes coisas e tão alheias a si mesmo, deve ocorrer somente após ocuparse com o que está mais próximo a si, para descobrir as pequenezas do seu interior. Por conseguinte, o princípio de cuidar de si mesmo estaria em toda conduta moral e racional.

Em Sócrates, o cuidado de si possui vários aspectos particulares, sendo o principal deles o conceito que reitera a atitude. Esta atitude seria para consigo, com os outros e para o mundo. Em segundo lugar, o cuidado de si é tido como uma forma de converter o olhar exterior dos outros para "si mesmo", sendo que: "O cuidado de si implica em uma maneira de estar atento ao que se pensa e ao que se passa no pensamento" (FOUCAULT, 2006, p. 14). Outra questão importante é que as ações devem ser exercidas de si para consigo. Estas ações de si para consigo na Grécia Antiga, de acordo com Foucault (2006), são importantes e capazes de modificar e transfigurar as pessoas.

Dessa forma:

Sócrates 'pensava que não se pode ser justo sozinho', ou seja, que não pode haver vida feliz para um cidadão quando toda uma cidade vive sob o signo da injustiça. Daí o compromisso assumido de empreender a tarefa de examinar não só a si mesmo, mas também os outros. $O$ cuidado de si não se opõe ao cuidado da cidade (SANTOS, 2008, p. 19).

Observa-se como visto acima que o cuidado de si está intrinsecamente relacionado ao cuidado com a cidade, logo com o cuidado do outro. Ou seja, deve-se primeiramente cuidar de si para em segundo lugar poder governar o outro. Percebe-se também que, no período socrático as vidas virtuosa e saudável são correlatas e que o homem virtuoso é o homem que conhece a si mesmo e esse conhecer leva ao cuidado de si que na época era um privilégio estatutário, presente apenas na dimensão política, econômica e social. Percebe-se assim, a identidade do sujeito e sua relação com o outro e como este outro tem a possibilidade de emergir quando bem trabalhada a questão do cuidado de si, a fim de tornar-se capaz de governar o outro com sabedoria e justiça. Assim, " "[...] ]em uma série de textos tardios (nos estóicos, nos cínicos, em Epicteto principalmente) Sócrates é sempre, essencial e fundamentalmente, aquele que interpelava os jovens na rua e lhes dizia: É preciso que cuideis de vós mesmos" (FOUCAULT, 2006, p. 11).

Dessa maneira, tem-se em Sócrates um mestre para Alcebíades o qual conduz o cuidado de si para cuidar do outro como será enfatizado a seguir.

\section{O cuidado de si tendo o outro como finalidade}

Foucault (2006) coloca que para Sócrates o cuidado de si tem como conseqüência o cuidado do outro, de modo a incitar em Alcebíades o que traria a justiça ao povo ateniense. Este trabalho que Sócrates tem por dever exercer com Alcebíades é devido a sua educação deficitária e enfraquecida por conta de seu instrutor ser um velho escravo, cujo era tido como ignorante.

Sócrates, segundo Foucault (2006), dizia a Alcebíades apenas é possível governar se seus esforços voltarem para si mesmo de modo reflexivo e comparativo a seus rivais. É a partir desta 
comparação que Alcebíades perceberia sua inferioridade perante os outros povos, principalmente os espartanos, pois estes possuíam os Hilotas para realização das tarefas diárias, ao passo que pudessem se ocupar consigo mesmo e serem verdadeiros guerreiros (FOUCAULT, 2006).

À vista disso, o cuidado de si é correlato ao exercício de poder e consequiência estatutária - que não deve ser considerado apenas como um privilégio -, mas sim uma condição que conduziria o herdeiro, como no caso de Alcebíades, a ação política efetiva na e para a cidade. Por conseguinte:

O 'ocupar-se consigo' está, porém, implicado na vontade do indivíduo de exercer o poder político sobre os outros e dela decorre. Não se pode governar os outros, não se pode bem governar os outros, não se pode transformar os próprios privilégios em ação política sobre os outros, em ação racional, se não se está ocupado consigo mesmo (FOUCAULT, 2006, p. 48).

Sócrates retrata que os jovens herdeiros desde a mocidade são constituídos de ambição, com a finalidade de prevalecer uns sobre os outros e triunfar sobre os rivais da cidade em uma política ativa e autoritária. Mas a questão apontada por Sócrates é o que daria legitimidade a este jovem herdeiro ao triunfar sobre alguém? De certo não será, como apontado por Foucault (2006), a sua grande fortuna, nem seu simples pertencimento ao meio aristocrático, mas sim um elemento muito mais profundo. Ou seja, seria a capacidade de governar o outro de maneira justa e sábia, e o meio para isso é a ocupação consigo mesmo.

Mas até que ponto este "ocupar-se consigo" faria um governante transformar-se em alguém que promove a justiça e como este cuidado de si retorna para a sociedade em forma de cuidado com o outro? Quando se cuida de si, o seu ser passa a desconsiderar pequenezas a fim de ter e sentir menos ambição e inveja, seu pensamento torna-se, por consequiência, algo mais fluído e eficaz no governo do outro. Por isso, se eu cuido de mim e melhoro as formas de governo eu estou cuidando do outro. Já um governante que não tem por objetivo este tipo de exercício - de cuidar de si e ocupar-se consigo mesmo - pode tomar decisões não tão sensatas e que desconsidere o outro e si mesmo como finalidade, pois não teria a capacidade de centrar o que é importante. Faz-se necessário e preciso escolher o que é útil e o que não é útil pra si e para o outro.

Ainda sobre o cuidado de si e do outro Foucault coloca que:

O cuidado de si é ético em si mesmo; mas ele implica em relações complexas com os outros, na medida onde esse éticos de liberdade é também uma maneira de cuidar dos outros; eis porque é importante para um homem livre que se conduz como se deve, saber governar sua mulher, seus filhos, sua casa. É aí também a arte de governar. O éticos envolve uma relação com os outros na medida onde cuidar de si possibilita ocupar, na cidade, na comunidade, ou nas relações interindividuais, o lugar que convém; seja para exercer a magistratura, ou para ter relações de amizade. E mais, cuidar de si implica ainda a relação com o outro na medida em que, para cuidar bem de si é necessário escutar as lições do mestre (apud MENDONÇA, 2012, p. 58).

Ademais, observa-se que o cuidado de si tem como finalidade o cuidado e a relação com os outros. O cuidado dos outros, desta maneira, faz-se presente em todo o desenvolvimento do conceito cuidado de si. 


\section{O cuidado de si e as mulheres na Grécia antiga}

Tem-se na História da Grécia oposições complementares socialmente, como exemplos: o homem livre e o escravo, rico e pobre, homem e mulher e civilizado e bárbaro. Mas como eram esses processos sociais na pólis? Como estas pessoas tão diferentes se integravam? Adentrando, deste modo, a questão de identidade e alteridade. Identidade sendo constituída por si mesmo e alteridade significando o outro. Este outro no contexto da Grécia Antiga por mais que afastado tem funções próprias e tão importantes dentro do cenário da pólis quanto as funções do cidadão.

Desta forma, observa-se que as mulheres são um dos "outros" presentes na pólis, de maneira hierárquica e constitui uma das esferas da sociedade ateniense. Há de se entender também que estes grupos compostos pelos outros da pólis são heterogêneos. Um dos principais fatores que diferenciam, por exemplo, os diversos grupos femininos é a condição social, assim como importante para os homens e herdeiros, a questão se colocava de mesmo modo para as mulheres. Seu status social também era importante, caracterizado como livre ou escrava, esposa ou prostituta e o estatuto social, ou seja, com quem estas mulheres eram casadas. Além disso, estas mulheres conheciam o seu lugar de atuação na sociedade e utilizavam disso como tática de participação social. (LESSA, 2004).

Em suma, as mulheres como pertencentes do grupo dos “outros” na Grécia Antiga deveriam, portanto, ser governadas, como visto anteriormente, por um herdeiro com capacidade de cuidado de si mesmo e capacidade de, a partir deste cuidado, conseguir governar o outro de maneira justa. Mas, de todo modo, por que o cuidado de si não pode ser aplicado às mulheres de Atenas? Ou seja, por que estas mulheres não poderiam exercer o cuidado de si ou por que estas mulheres não foram mencionadas em Sócrates? Esta é uma linha tênue, que deve ser trabalhada com cuidado para não remeter o trabalho a certo anacronismo, como será esclarecido abaixo.

O cuidado de si tem características próprias na Grécia antiga e os papéis femininos desempenhados neste período não correspondiam ou não possibilitavam às mulheres o cuidado de si mesma. Sua educação era na maioria das vezes feita por suas mães, as quais não tinham por finalidade ensinar um pensamento, mas sim ensiná-las a cuidar do outro, sendo neste caso o outro seu marido e seus filhos. Quando a mulher se casava este papel de educador passava a ser do marido. Lógico que isso não quer dizer que as mulheres não aprendiam sozinhas, mas sim que neste tempo histórico, não lhes era dada esta possibilidade, até mesmo devido ao fato de não serem consideradas cidadãs.

A mulher aparece nos textos marcada pela ausência do logos, o que a impossibilitava de participar da vida pública. Desta forma a subordinação da mulher ao homem pode ser verificada, inclusive, no domínio da palavra, onde as vozes das mulheres, desprovidas do logos, pareciam sempre dissonantes como gritos agudos ou lamentos (LESSA, 2004, p. 74).

Contudo, observa-se que a sociedade ateniense antiga tinha como objetivo manter as mulheres distanciadas da esfera de ação masculina. Autores antigos como Semônides, Sófocles e Aristóteles colocam em seus textos como o silêncio é uma virtude inerente ao comportamento ideal de uma mulher - esposa legítima -, bem como o ouvir era valorizado, tido como modelo exemplar (LESSA, 2004). Além disso, a mulher que expunha sua fala em público, neste período, era considerada indecente e poderia estar colocando a pólis em risco (PERROT, 2017).

Mas não cabia à mulher ateniense apenas os papéis de dona de casa, reservado ao ambiente privado. Muitas vezes a estas mulheres era designado o papel da tecelagem, artesanato e/ou costura. Estas atividades dependem de sua classe, às vezes seria para consumo próprio, mas algumas vezes para manutenção do oikós, apresentada como uma das virtudes femininas. 
Isto, segundo Xenofonte, era visto como uma qualidade - no caso de a mulher saber fazer estas atividades antes de se casar. Outro elemento singular é a utilização destes afazeres para encontrar-se com outras mulheres (LESSA, 2004).

Por conseguinte, havia outra singularidade que excluía as mulheres deste cuidado de si para os socráticos - a vaidade -, pois era incentivada nas mulheres desde muito pequenas. Suas mães ensinavam a cuidar de seus corpos, bem como aprender a arte da sedução, para tanto era costumeiro as mulheres usarem diversos adornos. Somente o fato de as mulheres serem vaidosas já as excluiria de aplicarem o cuidado de si a si mesmas. Já que o cuidado de si é uma maneira do homem compreender a sua subjetividade, o qual, em um jogo de verdades, acaba por se conhecer e relacionar consigo mesmo.

Ou seja, o sujeito dotado de cuidado de si, torna-se objeto de seu conhecimento, levado a se observar, conhecer e analisar. Assim, não remanesce espaço para as pequenezas da vida, como a vaidade e o olhar ao espelho, símbolo feminino na Grécia Antiga, retratado sempre nas mãos das mulheres em pinturas e vasos arqueológicos (LESSA, 2004). Pode-se ressaltar de antemão que o cuidado de si consiste em uma atitude consigo e para com os outros, pois colocaria em práticas ações pensando no outro e em si mesmo.

Diferentemente do pensamento de Sócrates, na República ideal de Platão estas mulheres teriam espaço tanto quanto os homens. Isto não quer dizer que Platão entendia que ambos os sexos fossem iguais na época em que escreveu, mas sim, que possuía um sentido apurado e não limitado ao que pensava de uma sociedade que buscava justiça.

Segundo Jaeger (1995), Platão coloca que as mulheres devem ter tanto espaço educacional quanto os homens, merecendo o direito a cultura e a ginástica, com a mesma finalidade de seus guardiões, ou seja, proteger a comunidade e proteger criadoramente a vida destes. Tendo em vista que para Platão as mulheres podem exercer estas atividades de cunho masculino - para a época- é possível, dentro desta perspectiva, que as mulheres também se reservassem ao cuidado de si. Para Jaeger, Platão demonstra como seria interessante se mulheres atenienses desempenhassem papéis tão importantes para a sociedade quanto as guerreiras espartanas. Logo, se cabia a estas mulheres o mesmo papel de um homem, as mesmas também poderiam exercer o pensamento de cuidado de si.

Outro ponto de destaque, dentre o cuidado de si para as mulheres em Platão, é que as mesmas deveriam poder, assim como os homens, desnudar-se e fazer exercícios, não só as novas como as mais velhas. Para ele se o homem já idoso o pode fazer a mulher também o pode. Para ele não havia nada de vergonhoso e sem moral neste ato, com uma sensibilidade muito maior do que a de seus antepassados, que viam este fato como vexatório (JAEGER, 1995).

\section{As mulheres contemporâneas e o cuidado de si}

Por mais que séculos tenham se passado algumas questões sobre o gênero feminino ainda permanecem em debate na atualidade. Uma destas questões, como apontado por Perrot (2005), é o espaço das mulheres na sociedade, vista ainda como uma história dos excluídos. A mulher foi, durante muito tempo, designada apenas a tarefas domésticas e mesmo hoje carrega-se um pouco deste fardo conservador sobre o gênero feminino. Coube às mulheres durante muitos anos o silêncio, como visto na Grécia Antiga; este silêncio seguiu-se até meados no século XIX. Ainda segundo Perrot (2017), este silêncio ocorreu no relato da história que não teve por finalidade incluir as mulheres em seus livros e análises, pois no início na Grécia Antiga e em Roma apenas preocupava-se com: 
[...] Espaço público: as guerras, os reinados, os homens 'ilustres', ou então os 'homens públicos'. O mesmo ocorre com as crônicas medievais e as vidas de santos: fala-se mais de santos do que de santas. Além disso, os santos agem, evangelizam, viajam. As mulheres preservam sua virgindade e rezam. Ou alcançam a glória do martírio, que é uma honra suntuosa. As rainhas merovíngias, tão cruéis, as damas galantes do renascimento, as cortesãs de todas as épocas fazem sonhar. É preciso ser piedosa ou escandalosa para existir (PERROT, 2017, p. 18).

Por um lado, este silêncio também foi devido à falta de fontes, dada a alfabetização tardia, tem-se pouquíssimos registros destas mulheres no percurso dos séculos. Sua produção doméstica esvaia-se muito rapidamente e estas mulheres não preservavam alguns objetos por os julgarem sem interesse aos outros. Mas, no século XIX a história torna-se mais científica, trouxe um pouco mais de espaço para estas mulheres. Tornaram-se comuns biografias de rainhas, santas e cortesãs. Ademais, foi entre as duas grandes guerras que as mulheres tiveram acesso à universidade e, a partir disto, se tornaram mais presentes na história e passaram a não ser tão silenciadas como antes (PERROT, 2017).

Estas questões nada mais são do que resultado de anos de lutas que se seguiram atrás de direitos iguais, para todos os cidadãos e não apenas direitos iguais aos homens. Estas lutas por direitos iguais começaram durante a primeira onda feminista, tem cunho intelectual, filosófico e político, visa reestabelecer padrões pré-estabelecidos pela sociedade. Esta primeira onda data mais ou menos do século XIX, desenvolvida principalmente na Inglaterra. A Inglaterra é considerada berço desta onda feminista devido à Revolução Industrial e à utilização de mulheres como mão de obra nas fábricas.

De todo modo, mesmo após dois séculos, as mulheres ainda lutam por espaço no lugar de trabalho, por melhores condições e pelo direito de exercer cargos tão importantes quanto os dos homens. É neste âmbito que se configura o cuidado de si na contemporaneidade, é na transformação do conceito cuidado de si que se tem a possibilidade de empregá-lo atualmente. Para Foucault (2006), é de suma importância a aplicação do cuidado de si na atualidade e este é o exercício que quer que façamos.

Nos dias de hoje, diferentemente da época socrática e platônica, o cuidado de si tem características muito mais particulares, pensadas e praticadas através do autoconhecimento e do auto exercício que são imprescindíveis ao que o indivíduo deve fazer sobre si na busca daquilo que é compreendido como sucesso e que trará felicidade de alguma forma. Por isso, quando as mulheres saem em luta por seus direitos, pode-se dizer que exercem o cuidado de si. Aperfeiçoa-se, portanto, sua vida profissional e demonstra que elas são a finalidade de sua própria felicidade.

Ou seja, não precisam que homens exerçam sobre elas algum tipo de atividade e que estão dispostas a lutar contra qualquer forma de alienação de seus direitos. Mas esta prática não seria egoísta? Por mais que o pensamento acerca do cuidado de si tenha sido modificado através do tempo, o mesmo ainda não se configura como um cuidado egoísta, mas sim uma prática de tornar o objeto sujeito de suas próprias verdades, mesmo que de maneira um tanto quanto mais individualizada. Quando uma mulher vai à luta pedir por direitos iguais ela não pensa apenas em si, pensa num todo. É de maneira arquitetada ou visa benefícios próprios? Sim, mas ao mesmo tempo se a ela são concedidos estes direitos também os são concedidos às outras mulheres. Logo, a finalidade da ação tem como característica o cuidado do outro e é incaracterístico de uma ação egoísta. Um pouco parecido com o que ocorria para Sócrates, só que com os homens governantes. A única diferença é que na atualidade isto também pode ser contemplado pelas mulheres.

Por mais que o cuidado de si na atualidade se distancie do cuidado do outro, ele ainda expressa uma ética baseada em métodos de conhecimento de si, autoexercício e 
aprimoramentos do eu, mas que não devem buscar apenas a realização financeira e pessoal. Já que, na perspectiva de Foucault (2006), na atualidade o cuidado de si pressupõe o conhecimento de si e culmina em uma introspecção ou volta a si mesmo como possibilidade de conhecer a natureza e sua espiritualidade. Ou seja, uma espécie de vigilância ou cuidado que o indivíduo deve ter sobre si mesmo para atingir suas virtudes e ações subjetivas. Transforma e modifica seu eu para possibilitar modos de estar e agir sobre e no mundo.

Ademais, percebe-se que o conceito de cuidado de si, na era socrática e platônica, pode ser visto de maneira mais contemplativa enquanto que na atualidade esse cuidado de si pode ser visto de maneira mais enérgica, como práticas de aperfeiçoamento da vida humana, com características importantes na formação das sociedades contemporâneas. Assim, observa-se que é através deste tipo de cuidado de si na atualidade que mulheres conseguiram maiores tolerâncias, quebra de tabus, opinião própria, liberdade de ir e vir, explorar sua sexualidade, pode sair do espaço privado, do interior das casas, para atuar no espaço público. Seja trabalhando, seja exercendo cargos de estatais como os homens os podem exercer.

Claro que um dos principais motivos que desencadearam a saída da mulher do espaço privado para o público talvez tenha sido a Segunda Guerra Mundial. Quando mulheres, querendo ou não, precisaram sair desta esfera para organizar a esfera pública refém de sua mão de obra enviada à guerra - o homem - assim foi visto que era possível que mulheres tivessem os mesmo trabalhos que os homens e a partir disto quando estes homens retornam para vossas casas, encontram mulheres dotadas de opinião, mulheres que querem ser agentes da história, querem ser participantes do mundo. Por meio do cuidado de si, do conhecimento de si e das práticas de si na atualidade essas mulheres perceberam que podiam ser mais, não de uma maneira egoísta, mas pensando também no outro. Não se vê uma mulher dizendo esse é meu direito, mas uma gama de mulheres que declaram esse é o "nosso" direito. A partir disso exercita o autocuidado, mas também o cuidado do outro.

\section{Considerações finais}

Foi problematizado nesse texto o conceito cuidado de si e quais os diálogos possíveis entre identidade e alteridade na Grécia Antiga, a partir do ponto de vista do lugar da mulher neste período e da maneira como o cuidado de si pode ser atribuído às mulheres na atualidade. Observou-se um campo inexplorado e um padrão social grego antigo, assim como a possibilidade para novos estudos, com a finalidade de preencher algumas lacunas que o artigo possa ter deixado ou encontrado em seu caminho.

Importante destacar que foram tomadas devidas precauções para que não houvesse nenhum anacronismo tanto da análise do lugar da mulher na sociedade grega antiga, bem como não houvesse emprego fora de seu tempo do conceito cuidado de si, já que o mesmo possui inúmeras análises. Utilizou-se, aqui, a análise em Sócrates e a aplicação do conceito por Foucault na atualidade.

Observou-se, também, que às mulheres atenienses não foi atribuído o direito ao cuidado de si, mediante seu status de não cidadã na época socrática, contudo as mesmas lidavam muito bem com o cuidado do outro, protegendo sua família, cuidado de seus filhos e marido, assim como, mantendo toda a estrutura privada intacta ainda que não tivesse lugar na vida pública. Mesmo que, embora, como visto no decorrer do artigo, as mulheres pudessem, para Platão, exercer atividades que envolvessem cultura, ginástica e música assim como os homens. Foram problematizadas, de semelhante modo, as lutas femininas na atualidade e como estas lutas sociais são exemplos de autocuidado e não apenas um cuidado egoísta. 


\section{Referências}

FOUCAULT, M. A hermenêutica do sujeito. Tradução de M. A. Fonseca e S. T. Muchail. São Paulo: Martins Fontes, 2006.

JAEGER, W. Paidéia: a formação do homem grego. Tradução de A. M. Parreira. 3.ed. São Paulo: Martins Fontes, 1995.

LESSA, F. S. O feminino em Atenas. Rio de Janeiro: Mauad, 2004.

MENDONÇA, A. G. Cuidar de si, cuidar dos outros: a alteridade no pensamento de Michel Foucault. Dissertação (Mestrado) - Departamento de Filosofia, Pontifícia Universidade Católica do Rio de Janeiro. Rio de Janeiro, 2011.

PERROT, M. Minha história das mulheres. Tradução de A. M. S. Corrêa. 2. ed. 5. reimp. São Paulo: 2017.

PERROT, M. As mulheres ou os silêncios da história. Tradução de V. Ribeiro. Bauru: Edusc, 2005.

RAMOS, E. D. Cuidado de si, práticas de si contemporâneas e discursos de autoajuda: uma leitura foucaultiana. Sapure Aude. Belo Horizonte, v. 7, n. 12, p. 240-255, 2016.

SANTOS, R. A. Sócrates e o cuidado de si ou a terapêutica da alma. Prometeus: filosofia em revista. São Paulo, v. 1, n. 02, p. 15-32, 2008. 